\title{
METHOD FOR CALCULATING TORSIONAL OSCILLATIONS IN EARTH'S ATMOSPHERE FROM NCEP/NCAR, MERRA-2, ECMWF ERA-40, AND ERA-INTERIM
}

\author{
O.S. Zorkaltseva \\ Institute of Solar-Terrestrial Physics SB RAS, \\ Irkutsk, Russia, meteorologist-ka@yandex.ru \\ V.I. Mordvinov \\ Institute of Solar-Terrestrial Physics SB RAS, \\ Irkutsk,Russia,v_mord@iszf.irk.ru, \\ Irkutsk State University
}

\author{
E.V. Devyatova \\ Institute of Solar-Terrestrial Physics SB RAS, \\ Irkutsk, Russia,devyatova@iszf.irk.ru
}

\author{
N.S. Dombrovskaya \\ Institute of Solar-Terrestrial Physics SB RAS, \\ Irkutsk, Russia, ndombrovskaya@inbox.ru
}

Irkutsk State University sional oscillations to study circulation dynamics of the atmosphere.

Keywords: general atmospheric circulation, torsional oscillations, troposphere, stratosphere, sudden stratospheric warming. NCEP/NCAR reanalysis I, MERRA-2, ECWMF 40, and ERA-Interim projects, using different methods of processing the original data. We estimate the degree of consistency of torsional oscillations, obtained from different reanalysis projects, and discuss the use of tor-

\section{INTRODUCTION}

Low-frequency variability of meteorological characteristics includes oscillations in the time range longer than the synoptic one, i.e. more than 7-10 days. The low-frequency oscillations have a spatial scale from thousands to several tens of thousands of kilometers or have a global scale, and their energy exceeds the energy in the synoptic range [Perevedentsev, 1984; Barnston, Livezey, 1987; Blackmon et al., 1977; Branstator, 1992]. The low-frequency variability can be driven by external excitation due to ocean temperature anomalies or moisture content in the soil; vacillation; possible existence of two or more circulation regimes; isolated vortices, solitons; wave-wave interactions; vorticity fluxes due to fluctuations having short time scales cyclones and anticyclones [Wallace, Blackmon, 1988]. Fundamentally different approaches are used to study the low-frequency variability in tropical and extratropical latitudes [Roger, Chorley, 2003; Lejenäs, Madden, 2000; Madden, 2007]. In midlatitudes, low-frequency (and largescale) anomalies are generally geostrophic. This greatly simplifies the analysis (not understanding) of the dynamics, structure, and sources of low-frequency disturbances. In the tropics, the geostrophic condition is worse fulfilled, and instabilities, caused by vertical temperature gradients and considerable latent heat fluxes, generate specific divergent and convergent dynamics with high vertical velocities.

The fact that the low-frequency variability has large spatial scales can be used to improve long-term weather forecasts and short-term climate forecasts, especially in the extratropical zone characterized by a high synoptic noise level. Information about behavior and features of low-frequency oscillations can be useful for studying the troposphere-stratosphere coupling, for example, when identifying predictors of sudden stratospheric warmings (SSW).

Of particular interest in the low-frequency range are variations in indices of Arctic and Antarctic oscillations, teleconnections [Blackmon et al., 1984a, b; Thompson, Wallace, 2000; Namias, 1981; Simmons et al., 1983], variations in the global atmospheric angular momentum [Egger, Weickmann, 2007; Egger et al., 2007], formation and decay of blocking anticyclones [Tung, Lidzen, 1979].

A special feature of the low-frequency variability is variations in zonally averaged meteorological values. Feldstein [1998] and Lee et al., [2007] have analyzed zonal-mean zonal wind variations on time scales $T \sim 60$ 100 days. Meridional drifts were determined using the regression analysis of wind velocity variations along different latitudes $\left(22.58^{\circ}, 45.08^{\circ}\right.$, and $66.58^{\circ} \mathrm{N}, 22.58^{\circ}$, $45.08^{\circ}$, and $\left.66.58^{\circ} \mathrm{S}\right)$. According to the results, at all latitudes a slow poleward drift prevails, which, in the authors' opinion, can be explained by the eddy momentum flux convergence under meridional nonadiabatic heating gradient. The mechanism proposed in [Feldstein, 1998] has been confirmed by model calculations [Lee et al., 2007].

The 10-40 day zonal-mean zonal wind variations differ from 60-100 day ones [Feldstein, 1998], for example, the variations we found in the 15-20 day range [Mordvinov et al., 2009a, b]. We call this phenomenon torsional oscillation. In this paper, we describe a method for calculating torsional oscillations, compare different ways of filtering initial data and torsional oscillations obtained from several reanalysis projects. Of particular interest is the calculation of torsional oscillations from ECMWF ERA and MERRA-2 data at heights exceeding the uppermost level of the NCEP/NCAR reanalysis.

\section{DATA AND METHODS}

The method for calculating torsional oscillations is quite simple and involve several stages. First, the daily 
zonal wind is averaged along different latitudes. Then the low-frequency fluctuations are isolated by means of the band-pass filters. In previous studies [Mordvinov, 2009a; Mordvinov, 2009b], we used the simple Bartlett filter, assuming that the results are not sensitive to the details of the filter shape. To test this assumption, we employ several linear smoothing filters with different impulse responses [Rozhkov, 2002]:

- Bartlett filter

$$
\lambda(\tau, T)=\left\{\begin{array}{l}
1 \text { when } \tau \leq T, \\
0 \text { when } \tau>T ;
\end{array}\right.
$$

- Hannah filter

$$
\lambda(\tau, T)=\left\{\begin{array}{l}
0.5\left(1-\cos \frac{\pi \tau}{T}\right) \text { when } 0 \leq \tau \leq T, \\
0 \text { when } \tau>T
\end{array}\right.
$$

- Hamming filter

$$
\lambda(\tau, T)=\left\{\begin{array}{l}
0.54+0.46 \cos \left(\frac{\pi \tau}{T}\right) \text { when } 0 \leq \tau \leq T, \\
0 \text { when } \tau>T
\end{array}\right.
$$

- Parzen filter

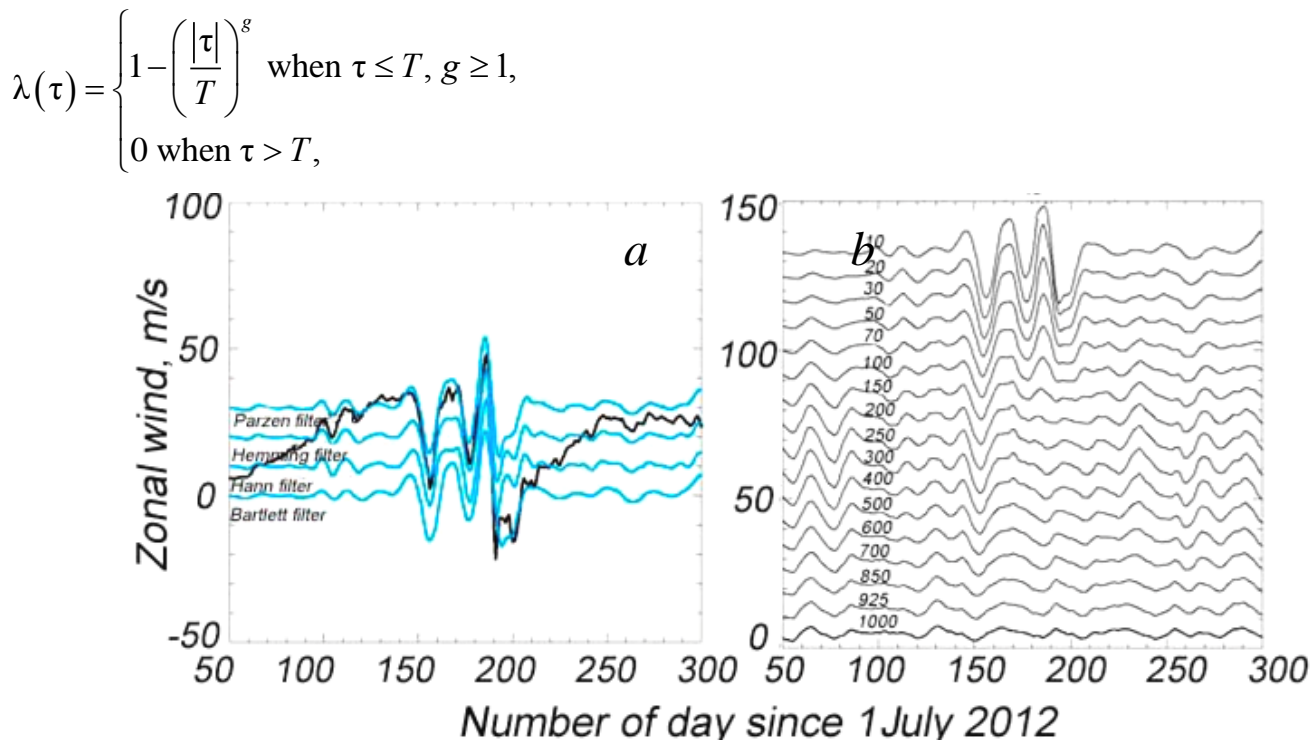

Figure 1. Zonal-mean zonal wind at $10 \mathrm{hPa}$ in the latitude range from 70 to $80^{\circ} \mathrm{N}$ in $2012-2013$ as derived from NCEP/ NCAR data (black curve) and results of their processing (blue curves) with the Bartlett, Hannah, Hamming, and Parzen filters, $t_{\min }=8$ days, $t_{\max }=30$ days $(a)$. Plots of unfiltered zonal-mean zonal wind variations and filtered values are vertically shifted for convenience of comparison. In the X-axis are numbers of days from July 1, 2012 to July 1, 2013. Changes of zonal-mean zonal wind variations from $1000 \mathrm{hPa}$ to 10 $\mathrm{hPa}$ in the $70-80^{\circ} \mathrm{N}$ latitude range, filtered by the Bartlett filter in 8 and 30-day band-pass $(b)$

To do this, we normalize the zonal-mean zonal wind to the difference between maximum and minimum values of time series at different latitudes

$$
f_{\mathrm{n}}=\left(f-f_{\min }\right) /\left(f_{\max }-f_{\min }\right) .
$$

Where $f, f_{\mathrm{n}}$ are nonnormalized and normalized series of daily zonal-mean zonal wind. The normalized zonalmean zonal wind at each latitude ranged from 0 to 1 .

The proposed method of processing time series has been applied to NCEP/NCAR, ECMWF ERA-40, and ERA-Interim data [Kalnay et al., 1996; Uppala et al,. where $T$ is the smoothing band-pass size.

Time series of the zonal-mean zonal wind have been processed twice - with $T=t_{\min }$ and $T=t_{\max }$. Then, we subtracted the second time series from the first one. With this processing method the resulting time series primarily included the variations with periods between $t_{\min }$ and $t_{\max }$; high-frequency and seasonal variations were excluded. Figure 1, $a$ exemplifies filtering of the zonal-mean zonal wind at $10 \mathrm{hPa}$ in 2012-2013 in the $70^{\circ}-80^{\circ} \mathrm{N}$ latitude range, using the Bartlett, Hannah, Hamming, and Parzen filters. Obviously there are no significant differences in the results. Figure $1, b$ plots the zonal-mean zonal wind variations which were filtered by the Bartlett filter at 17 pressure levels of the NCEP/NCAR reanalysis project in 2012-2013. Zonalmean zonal wind variations occur at all levels from the troposphere to the stratosphere; however, if in summer the velocity variations in the troposphere are quickly damped when propagating into the stratosphere, in winter in the stratosphere they increase, with amplitude several times as great as the amplitude of the zonalmean zonal wind variations in the lower troposphere.

To analyze the connection of the zonal-mean zonal wind variations at different latitudes, we eliminate the latitude dependence of their amplitude.
2005; Dee et al., 2011] with a spatial resolution of $2.5^{\circ} \times 2.5^{\circ}$ and to MERRA-2 data [Rienecker et al., 2011] with a resolution of $5.625^{\circ} \times 5^{\circ}$.

Figure 2 illustrates the result of the application of this technique, using the Bartlett filter. Figure 2, right, presents time-latitude cross-sections of torsional oscillations. Figure 2, left, presents unfiltered and unnormalized zonal-mean zonal wind variations from July 1, 2012 to July 1, 2013 at 500, 150, $10 \mathrm{hPa}$. It is seen that in the troposphere zonal-mean zonal wind variations slowly drift poleward on time scales 
of 100 days [Feldstein, 1998]. They have a completely different appearance after filtering and normalization (right panels in Figure 2) and represent oblique strips crossing the equator from north to south and from south to north.

The time-latitude cross-sections for the stratosphere (Figure 2, bottom panels) are more complex than those for the troposphere. All the cross-sections show pronounced seasonal variations there. The eastward wind in the low-latitude stratosphere is more intense than in the troposphere, and covers a wider range of latitudes. In summer, it propagates to high latitudes, thus leading to reduction or even disappearance of torsional oscillations. The thick line indicates the zonal mean temperature at $65^{\circ} \mathrm{N}$. We can see a close relationship between the torsional oscillations and the temperature variations. The temperature begins to rise when a torsional oscillation reaches the boundary of the stratospheric polar vortex.

\section{TORSIONAL OSCILLATIONS IN DIFFERENT WAYS OF FILTERING}

Figure 3 presents time-latitude cross-sections of torsional oscillations at $10 \mathrm{hPa}$ for the 2012-2013 winter, calculated from ERA data, using different filters in the 5-20-day range. We can see that the torsional oscillations have quite similar variance patterns. Their main feature is the short-duration variation in the middle of winter, propagating from low latitudes toward the North Pole. A plot of mean temperature variations at $65^{\circ} \mathrm{N}$ shows that this variation resulted in an abrupt temperature increase (SSW) [Kochetkova et al., 2014]. This example illustrates not only a weak dependence of torsional oscillations on the choice of a filter, but also the possibility of their use for predictions SSW [Kochetkova et al., 2014].
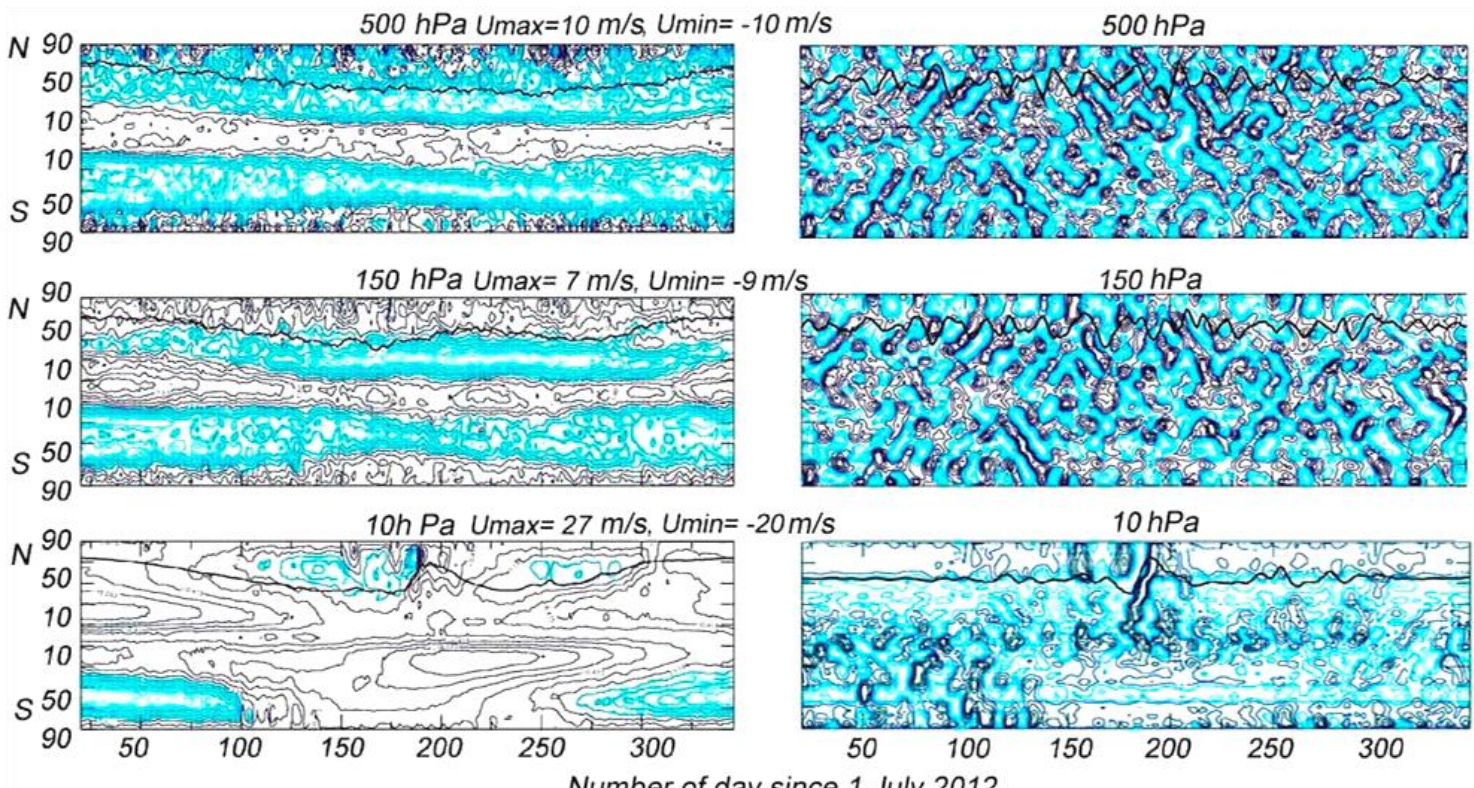

Figure 2. Zonal-mean zonal wind variations from July 1, 2012 to July 1, 2013 at 500, 150, 10 hPa: unfiltered (left); filtered in the 5-20-day range and normalized to the difference Umax-Umin during the period of interest (right). The 0.1-0.5 contours are shown by light blue lines; the $0.6-1$ range, by blue ones. The black solid curve indicates the zonal mean temperature at latitude of $65^{\circ}$ (NCEP/NCAR data)
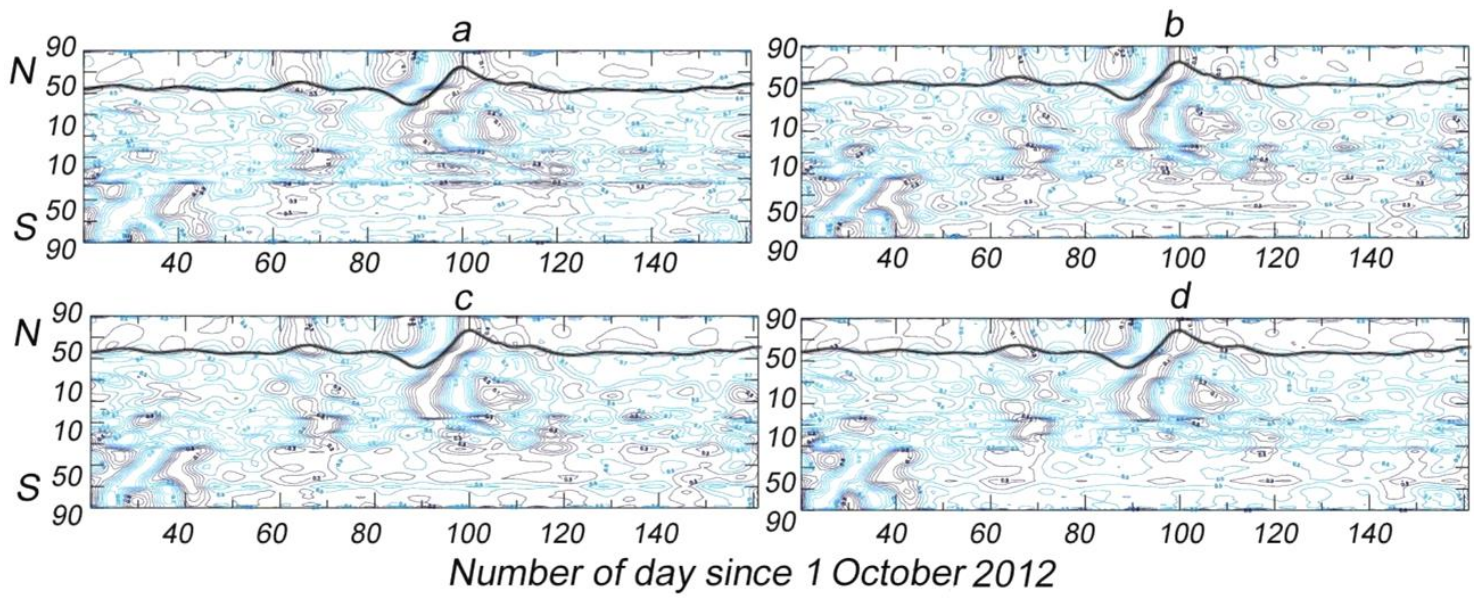

Figure 3. Time-latitude cross-sections of torsional oscillations calculated using the Bartlett $(a)$, Hannah $(b)$, Hamming $(c)$, and Parzen $(d)$ filters from October 20, 2012 to March 10, 2013. The black line is the zonal mean temperature at $65^{\circ} \mathrm{N}$ at $10 \mathrm{hPa}$ (NCEP/NCAR data) 
To quantify the dependence of torsional oscillations on the choice of a filter, we have calculated correlation coefficients between torsional oscillations obtained using the Bartlett, Hann, Hamming, and Parzen filters for five winter periods from 2012 to 2017 . The correlation coefficients were averaged over heights from 1000 to 1 $\mathrm{hPa}$. The calculation results are shown in Figure 4.

We can see that the correlation coefficients range from 0.7 to 0.95 . Assess the reliability of the estimated correlation coefficients. If we consider the distribution of sample values as normal (which is quite acceptable for a large number of measurements), the standard deviation of sample correlation coefficient $s$ will depend on the correlation coefficient $\rho$ and the number of degrees of freedom $n$ and will be calculated from the formula $s=\left(1-\rho^{2}\right) / \sqrt{n}$ [Korn, Korn, 1984]. If we assume that amplitudes of zonal-mean zonal wind variations at different times are statistically independent, then for $\rho=0.1$ and $n=140 s=0.04$. If we assume that the realizations consist of separate oscillation trains with random phases lasting 10 days, the number of degrees of freedom decreases approximately 10 times. In this case, $s=0.13$. Given that the sample correlation coefficients range, on average, from 0.7 to 0.9 , we can assume that for this $s$ value their estimates are sufficiently reliable.

The high correlation coefficients of the time series obtained using different smoothing filters mean that it does not really matter what filter is used for the analysis of torsional oscillations. We will therefore use the simplest Bartlett filter in further calculations.

\section{TORSIONAL OSCILLATIONS FROM DIFFERENT REANALYSIS DATA}

In this paper, we use data from NCEP/NCAR for 1950-2017, ECWMF ERA-40 for 1957-2002, ERAInterim for 1979-2017, and MERRA-2 for 1980-2017. The Reanalysis data differ in time and height (NCEP/NCAR, up to $10 \mathrm{hPa}$; ERA-Interim, up to $1 \mathrm{hPa}$; MERRA-2, up to $0.1 \mathrm{hPa}$ ). Reanalysis projects use different assimilation systems and different amount of observations.

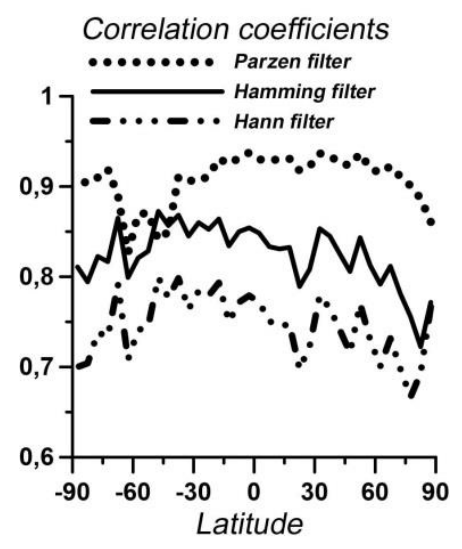

Figure 4. Correlation coefficients of torsional oscillations obtained using the Bartlett filter, and torsional oscillations identified using the Parzen, Hamming, and Hannah filters (ERA-Interim data)
Figure 5 shows the correlation coefficients between ECMWF ERA-40 and NCEP/NCAR torsional oscillations in the 5-20-day range in the middle troposphere $(500 \mathrm{hPa})$, upper troposphere $(150 \mathrm{hPa})$, and stratosphere $(10 \mathrm{hPa})$.

It is evident that the $10 \mathrm{hPa}$ plot differs significantly from the others. If the correlations coefficients for lower levels of the atmosphere are fairly complete, for the stratosphere a high values are observed only after the 1980s. For the 1970-80s, the correlation coefficients rarely exceed 0.5 . Since we have used long time series $(n=140)$, the estimated correlation coefficients are quite reliable. The high correlation coefficients in recent decades enable us to complement the calculations of torsional oscillations from one reanalysis project's data by the calculations from another virtually at all levels of the atmosphere. For the 1960-70s, the calculations for the stratosphere are less reliable, and they should be treated with great caution.

To analyze the dependence of correlation coefficients on spatial coordinates, we have constructed height-latitude cross-sections of correlation coefficients between NCEP/NCAR and ERA-Interim data (Figure 6, $a$ ) and ERA-Interim and MERRA-2 data (Figure 6, $b$ ) averaged over five winter periods from 2012 to 2017 . We compared unfiltered data, i.e. the zonal-mean zonal wind calculated using data from two reanalysis projects, and torsional oscillations obtained after normalizing and filtering data with the Bartlett filter in the 5-20-day range.

It can be seen that the torsional oscillations and distributions of zonal-mean zonal wind correlate well between NCEP/NCAR and ERA-Interim data and noticeably worse between ERA-Interim and MERRA-2 data, although the correlation coefficients are quite high (0.70.9 ) for the Northern Hemisphere. The greatest discrepancies between data from different reanalysis projects are observed in the equatorial zone above the tropopause (Figure 6, a, b). In Figure 6, b, there are also low correlation coefficients in the Southern Hemisphere. Unlike the zonal-mean zonal wind (Figure 6, a, right panel), torsional oscillations (Figure 6, a, left panel) according to ERA-Interim and NCEP/NCAR data correlate worse at equatorial latitudes and in the Southern Hemisphere. The comparison between MERRA-2 and ERA-Interim data (Figure 6, b) shows that filtering also reduces the correlation coefficients for the Southern Hemisphere, but increases them for the upper atmospheric layers of the Northern Hemisphere.

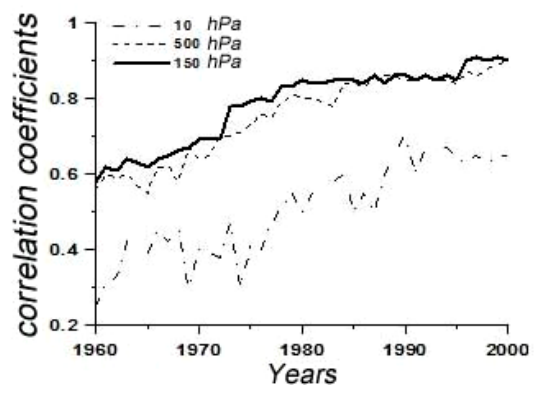

Figure 5. Correlation coefficients between torsional oscillations calculated from NCEP/NCAR and ERA-40 data 

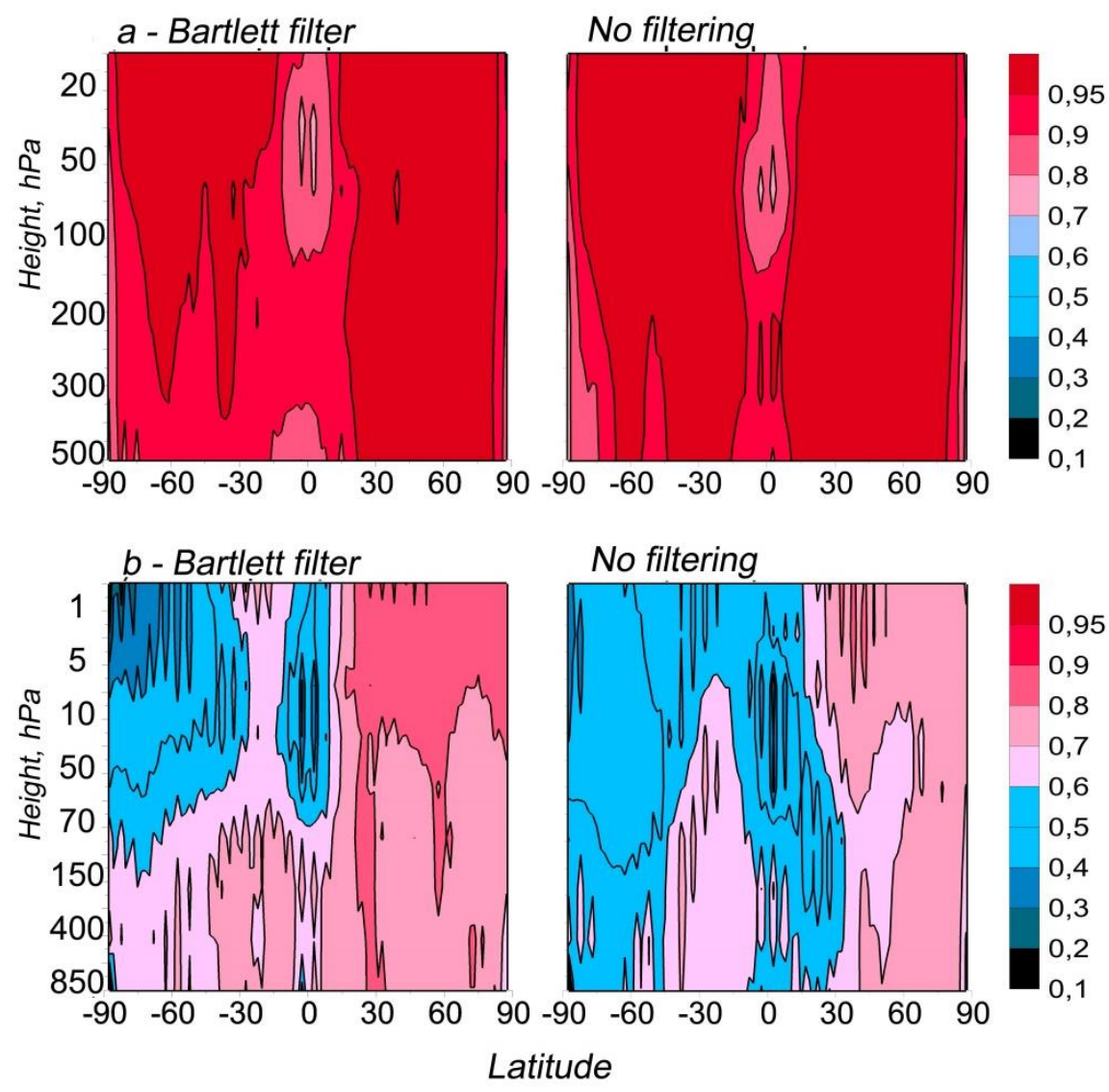

Figure 6. Correlation coefficients between zonal-mean zonal wind variations calculated from NCEP/NCAR and ERA-Interim data $(a)$ and from MERRA-2 and ERA-Interim data $(b)$

To search for the reasons of the differences between the reanalysis projects is beyond the scope of this work. In general, we have found that torsional oscillations are not sensitive to the details of the filter shape, so they are a really existing and quite noticeable phenomenon in the dynamics of the general atmospheric circulation. To study torsional oscillations, we can use various reanalysis data, which are largely interchangeable. The use of the reanalysis data for the equatorial region and MERRA-2 for the Southern Hemisphere requires a somewhat greater care.

\section{TORSIONAL OSCILLATIONS IN DIFFERENT BAND-PASS RANGES}

Natural processes, in particular meteorological, are rarely "narrowband". A change in the band-pass range can therefore cause a change in the pattern of the phenomenon, which often consists of small-scale and largescale features whose dynamics may differ, despite their being a part of one phenomenon. To reduce the dependence of the analysis results on the selected band-pass range, we made the filtering in three overlapping bandpass ranges 5-15, 10-20, and 15-25 days, and then multiplied the resulting time series. As a result, instead of three different time-latitude cross-sections we obtained one complex cross-section, which displayed features of torsional oscillations common to all the three band-pass ranges. Figure 7 gives an example of the construction of the complex time-latitude cross-section for 2000-2001. In the upper three panels there are time-latitude crosssections of torsional oscillations, constructed in 5-15, 10-20, and 15-25-day band-pass ranges. The bottom panel shows a time-latitude cross-section obtained by multiplying three top time-latitude cross-sections. It is seen that the complex time-latitude cross-section is simpler than those constructed for each band-pass range. Furthermore, since we normalized the time series in the range from 0 to 1 , negative anomalies were suppressed. This allowed us to simplify the pattern of torsional oscillations by reducing redundant information provided by negative velocity anomalies comprising a part of the train of torsional oscillations.

Figure 8 presents time-latitude cross-sections in three overlapping band-pass ranges and a complex time-latitude cross-section of torsional oscillations in the stratosphere $(10 \mathrm{hPa})$. Unlike the troposphere (Figure 7$)$, in the stratosphere the pattern of torsional oscillations remains virtually unchanged: all time series exhibit well-defined anomalies propagating from low latitudes and preceding SSW.

\section{RESULTS AND DISCUSSION}

The question about mechanism and generation sources of torsional oscillations is still open. Characteristic oscillations in the 5-25-day periods in different meteorological parameters occur in almost all seasons and at all heights of the atmosphere. 


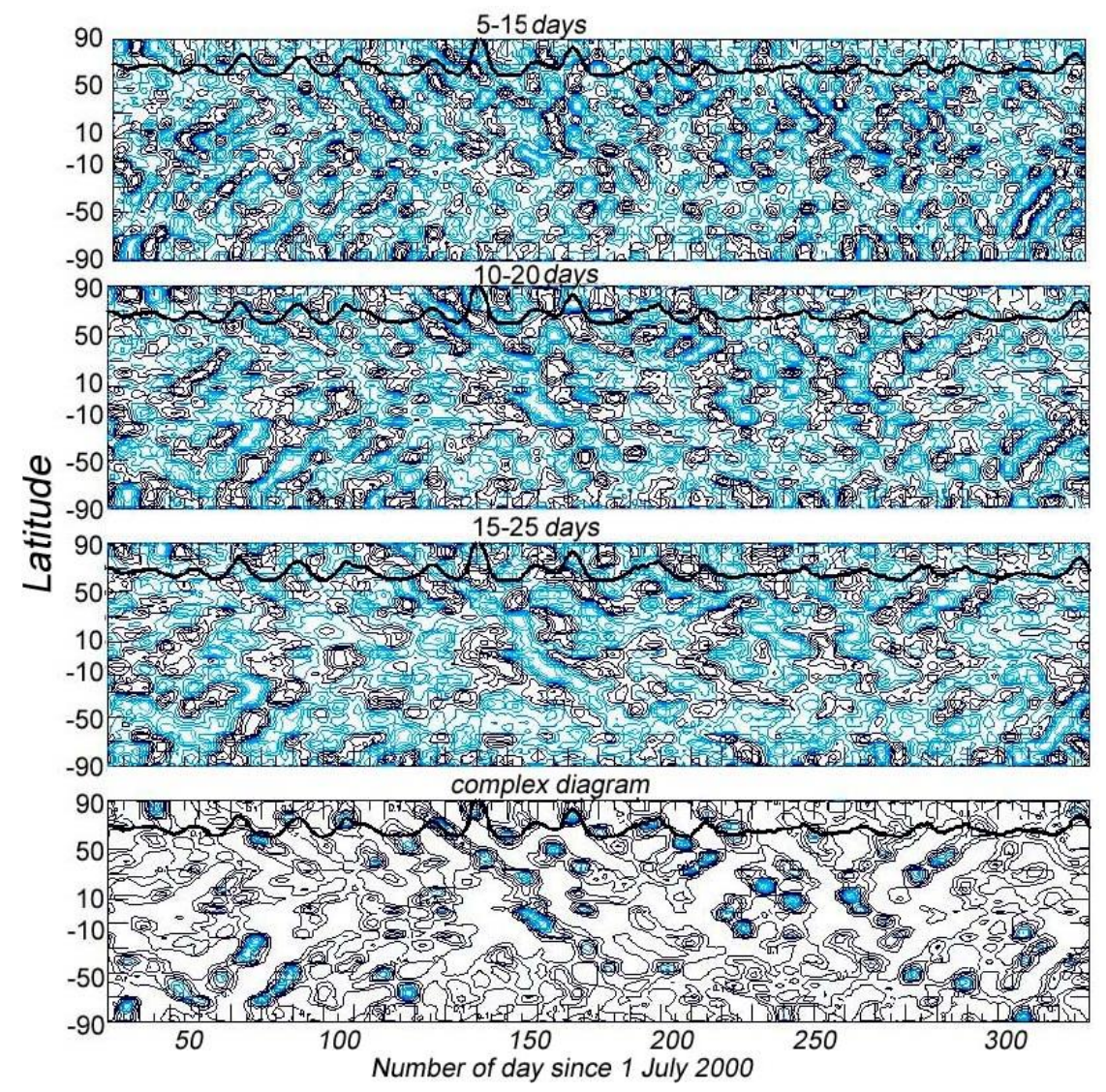

Figure 7. Time-latitude cross-sections of torsional oscillations in 2000-2001 at $500 \mathrm{hPa}$ constructed using the Bartlett filter with 5-15, 10-20, 15-25-day band-pass, and a complex time-latitude cross-section (Era-Interim data)

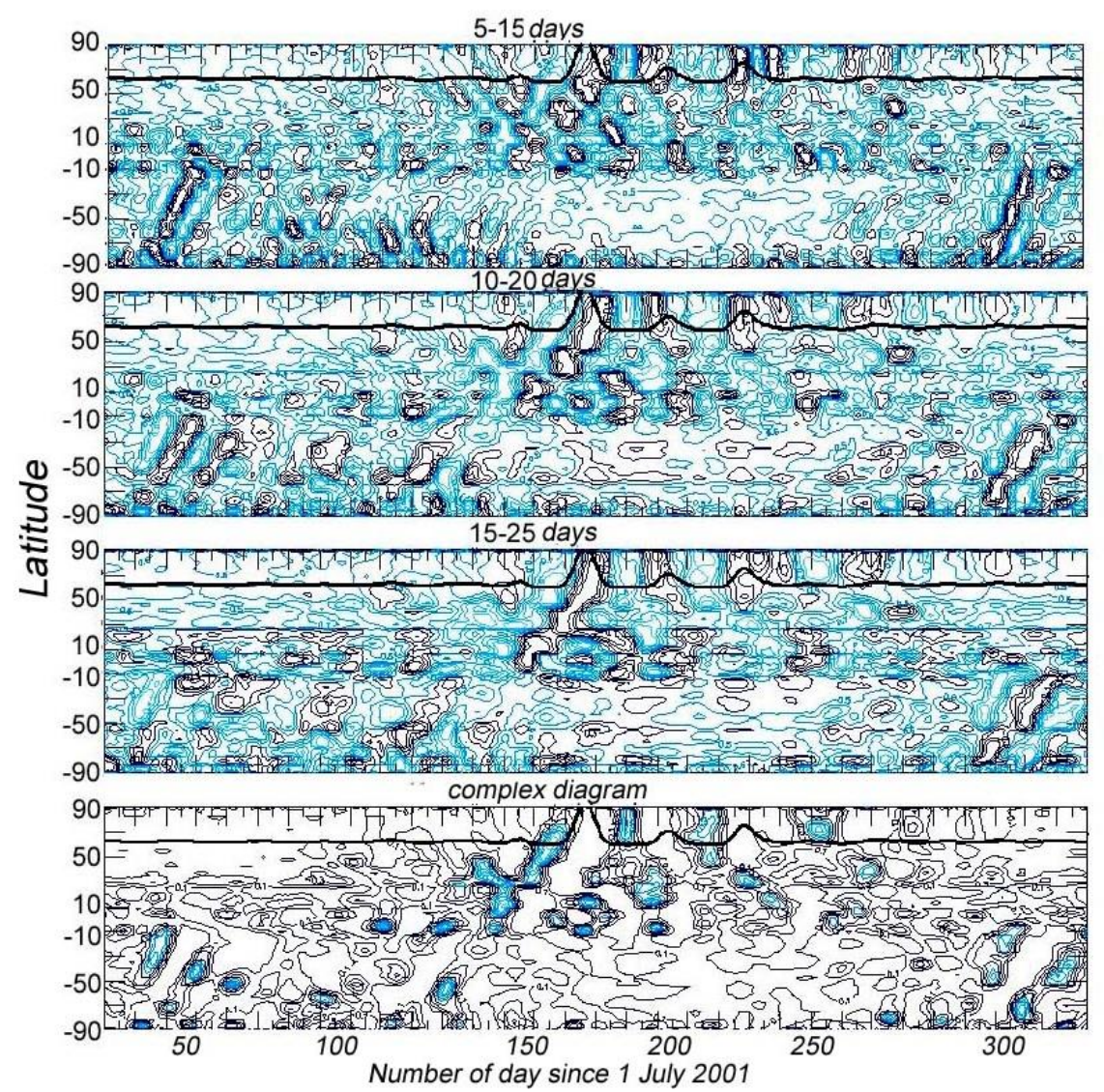

Figure 8. Time-latitude cross-sections of torsional oscillations in 2001-2002 at $10 \mathrm{hPa}$, constructed using the Bartlett filter with 5-15, 10-20, 15-25 day band-pass, and a complex time-latitude cross-section (Era-interim data) 
This suggests that this phenomenon is global. A remarkable feature of these oscillations is that they can be connected with such phenomena as Arctic and Antarctic oscillations; and in the upper atmosphere, with sudden stratospheric warmings. Kochetkova et al. [2014], studying SSW in the middle stratosphere, have shown that propagation of torsional oscillations from adjacent latitudes is one of the factors contributing to SSW. This means that torsional oscillations can be a tool for studying dynamics of the winter stratosphere.

\section{CONCLUSION}

In this paper, we have described in detail the method for calculating torsional oscillations - zonal-mean zonal wind variations in the 5-25-day periods. We have compared different methods of data filtering (Bartlett, Parzen, Hamming, and Hannah filters). With these filters there was good agreement between results, therefore in further studies we employed the simplest of them - the Bartlett filter. This filter was used to calculate torsional oscillations from NCEP/NCAR Reanalysis I, MERRA-2, ECWMF ERA-40, and ERA-Interim data. The comparison showed a close correlation between torsional oscillations according to NCEP and ERA data in the troposphere from 1980 (correlation coefficients 0.8-0.9).

For the stratosphere, the correlation is worse for the 1960-70s, but after 1980 the correlation coefficients also reached quite high values $(0.65-0.7)$. The comparison of torsional oscillations for the current period, made for ERA and NCEP, ERA and MERRA-2, has shown that torsional oscillations and distributions of zonal-mean zonal wind correlate well between NCEP/NCAR and ERA data (0.9$0.95)$ and somewhat worse between ERA and MERRA-2 data, although the correlation coefficients for the Northern Hemisphere are also quite high (0.7-0.9). Significant discrepancies between data from different reanalysis projects are observed in the equatorial zone above the tropopause. Despite the fact that the use of the reanalysis projects for the equatorial region and MERRA-2 for the Southern Hemisphere requires some caution, all the reanalysis projects are largely interchangeable. The dependence of torsional oscillations on the filtering range is mainly eliminated when using complex time-latitude cross-sections.

We thank Kandieva Kanykei Kubanychevna, a graduate student at the Russian State Hydrometeorological University (St. Petersburg), for her assistance in preparing MERRA-2 data.

The work was performed with budgetary funding of Basic Research program II.12 (projects II.16.1.1) for 2013-2020.

\section{REFERENCES}

Barnston A.G., Livezey R.E. Classification, seasonality, and persistence of low-frequency atmospheric circulation patterns. Mon. Wea. Rev. 1987, vol. 115, pp. 1083-1126. DOI: 10.1175/1520-0493(1987)115<1083:CSAPOL>2.0.CO;2.

Blackmon M.L., Wallace J.M., Lau N., Mullen S.L. An observational study of the Northern Hemisphere wintertime circulation. J. Atmos. Sci. 1977, vol. 34, pp. 1040-1053. DOI: 10.1175/ 1520-0469(1977)034<1040:AOSOTN>2.0.CO;2.

Blackmon M.L., Wallace J.M., Lee Y.-H. Horizontal struc- ture of 500-mb height fluctuations with short, medium and long time scales. J. Atmos. Sci. 1984a, vol. 41, pp. 961-979. DOI: 10.1175/1520-0469(1984)041<0961:HSOMHF>2.0.CO;2.

Blackmon M.L., Wallace J.M., Lee Y.-H., Hsu H.-H. Time variation of 500-mb height fluctuations with short, medium and long time scales. J. Atmos. Sci. 1984b, vol. 41, pp. 981-991. DOI: 10.1175/1520-0469(1984)041<0981:TVOMHF>2.0.CO;2.

Branstator G. The maintenance of low-frequency atmospheric anomalies. J. Atmos. Sci. 1992, vol. 49, pp. 1924-1945. DOI: 10.1175/1520-0469(1992)049<1924:TMOLFA>2.0.CO;2.

Dee D.P., Uppala S.M., Simmons A.J., Berrisford P., Poli P., Kobayashi S., Andrae U., Balmaseda M.A., Balsamo G., Bauer P., Bechtold P., Beljaars A.C.M., van de Berg L., Bidlot J., Bormann N., Delsol C., Dragani R., Fuentes M., Geer A.J., Haimberger L., Healy S.B., Hersbach H., V. Hólm E., Isaksen L., Kållberg P., Köhler M., Matricardi M., McNally A.P., MongeSanz B.M., Morcrette J.J., Park B.K., Peubey C., de Rosnay P., Tavolato C., Thépaut J.-N., Vitart F. The ERA-Interim reanalysis: configuration and performance of the data assimilation system. $Q$. J. R. Meteorol. Soc. 2011, vol. 137, pp. 553-597. DOI: 10.1002/qj.828.

Egger J., Weickmann K.M. Latitude-height structure of the atmospheric angular momentum cycle associated with the Madden-Julian oscillation. Mon. Weather Rev. 2007a, vol. 135, no. 4, pp. 1564-1575. DOI: 10.1175/MWR3363.1.

Egger J., Weickmann K.M., Hoinka K.-P. Angular momentum in the global atmospheric circulation. Rev. Geophys. 2007b, vol. 45. DOI: 10.1029/2006RG000213.

Feldstein S.B. An observational study of the intraseasonal poleward propagation of zonal mean flow anomalies. $J$. Atmos. Sci. 1998, vol. 55, pp. 2516-2529. DOI: 10.1175/15200469(1998)055<2516:AOSOTI>2.0.CO;2.

Kalnay E., Kanamitsu M., Kistler R., Collins W., Deaven D., Gandin L., Iredell M., Saha S., White G., Woollen J., Zhu Y., Chelliah M., Ebisuzaki W., Higgins W., Janowiak J., Mo K.C., Ropelewski C., Wang J., Leetmaa A., Reynolds R., Roy J., Dennis J. The NCEP/NCAR 40-year reanalysis project. Bull. Amer. Meteor. Soc. 1996, vol. 77, pp. 437-470. DOI: 10.1175/15200477(1996)077<0437: TNYRP>2.0.CO;2.

Kochetkova O.S., Mordvinov V.I., Rudneva M.A. Analysis of factors affecting the origination of stratospheric warmings. Optika atmosfery $i$ okeana [Atmospheric and Oceanic Optics]. 2014, vol. 27, no. 8, pp. 719-727. (In Russian).

Korn G., Korn T. Mathematical Handbook for Scientific Workers and Engineers. Moscow, Nauka Publ., 1984. 831 p. (In Russian).

Lee S., Son S-W., Grise K., Feldstein S.B. A mechanism for the poleward propagation of zonal mean flow anomalies. $J$. Atmos. Sci. 2007, vol. 64, pp. 849-869. DOI: 10.1175/JAS3861.1.

Lejenäs H., Madden R.A. Mountain torques caused by normal-mode global Rossby waves, and the impact on atmospheric angular momentum. J. Atmos. Sci. 2000, vol. 57, pp. 1045-1051. DOI: 10.1175/1520-0469(2000)057<1045:MTCBNM>2.0.CO;2.

Madden R.A. Large-scale, free Rossby waves in the atmosphere - an update. Tellus. Series A: Dynamic Meteorology and Oceanography. 2007, vol. 59, iss. 5, pp. 571-590. DOI: 10.1111/ j.1600-0870.2007.00257.x.

Mordvinov V.I., Ivanova A.S., Devyatova E.V. Excitation of Arctic and Antarctic Oscillations by torsional vibrations. Solnechno-zemnaya fizika [Solar-Terr. Phys.]. 2009a, iss. 13, pp. 55-65. (In Russian).

Mordvinov V.I., Ivanova A.S., Devyatova E.V. Excitation of Arctic Oscillation by torsional vibrations. Optika atmosfery $i$ okeana [Atmospheric and Oceanic Optics]. 2009b, vol. 22, no. 2, pp. 1-8. (In Russian).

Namias J. Teleconnections of $700 \mathrm{mb}$ height anomalies for the Northern Hemisphere. CALCOFI. 1981, no. 29, 265 p.

Perevedentsev Yu.P. Circulation and energy processes in the middle atmosphere. Kazan, KSU Publ., 1984, 167 p. (In 
Russian).

Rienecker M.M., Suarez M.J., Gelaro R., Todling R., Bacmeister J., Liu E., Bosilovich M.G., Schubert S.D., Takacs L., Kim G.-K., Bloom S., Chen J., Collins D., Conaty A., da Silva A., Gu W., Joiner J., Koster R.D., Lucchesi R., Molod A., Owens T., Pawson S., Pegion P., Redder C.R., Reichle R., Robertson F.R., Ruddick A.G., Sienkiewicz M., Woollen J. MERRA NASA's Modern-ERA Retrospective Analysis for Research and Applications. J. Climate. 2011, vol. 24, pp. 3624-3648. DOI 10.1175/JCLI-D-11-00015.1.

Roger G.B., Chorley R.J. Atmosphere, Weather and Climate. Eighth edition by Routledge 11 New Fetter Lane. London EC4P 4EE. 2003, 421p.

Rozhkov V.A. Theory and Methods for Statistical Estimation of probabilistic characteristics of random variables and functions with hydrometeorological examples. Saint Petersburg, Gidrometeoizdat, 2002. 779 p. (In Russian).

Simmons A.J., Wallace J.M., Branstator G.W. Barotropic wave propagation and instability, and atmospheric teleconnection patterns. J. Atmos. Sci. 1983, vol. 40, no. 6, pp. 1363-1392. DOI: 10.1175/1520-0469(1983)040<1363:BWPAIA >2.0.CO;2.

Thompson D.W.J., Wallace J.M. Annular modes in the extratropical circulation, Part I: Month-to-month variability. $J$. Climate. 2000, vol. 13, pp. 1000-1016. DOI: 10.1175/15200442(2000)013<1000:AMITEC>2.0.CO;2.

Tung K.K., Lindzen R.S. Theory of stationary long waves. Part I: Simple theory of blocking. Mon. Wea. Rev. 1979, vol. 107, pp. 714-734. DOI: 10.1175/15200493(1979) 107<0714:ATOSLW>2.0.CO;2.
Uppala S.M., Kållberg P.W., Simmons A.J., Andrae U., da Costa Bechtold V., Fiorino M., Gibson J.K., J. Haseler, Hernandez A., Kelly G.A., Li X., Onogi K., Saarinen S., Sokka N., Allan R.P., Andersson E., Arpe K., Balmaseda M.A., Beljaars A.C.M., van de Berg L., Bidlot J., Bormann N., Caires S., Chevallier F., Dethof A., Dragosavac M., Fisher M., Fuentes M., Hagemann S., Hólm E., Hoskins B.J., Isaksen L., Janssen P.A.E.M., Jenne R., Mcnally A.P., Mahfouf J.-F., Morcrette J.-J., Rayner N.A., Saunders R.W., Simon P., Sterl A., Trenberth K.E., Untch A., Vasiljevic D., Viterbo P., Woollen J. The ERA-40 re-analysis. $Q$. J. R. Meteorol. Soc. 2005, vol. 131, iss. 612, pp. 2961-3012. DOI: $10.1256 /$ qj.04.176.

Wallace J.M., Blackmon M.L. The observable low-frequency variability of the atmosphere. Large-scale dynamic processes in the atmosphere. Moscow, Mir, 1988, pp. 66-109. (In Russian). English edition: Wallace J.M., Blackmon M.L. Observation of low-frequency atmospheric variability. Large-Scale Dynamical Processes in the Atmosphere. Academic Press, 1983, pp. 55-94.

How to cite this article

Zorkaltseva O.S., Mordvinov V.I., Devyatova E.V., Dombrovskaya N.S. Method for calculating torsional oscillations in Earth's atmosphere from NCEP/NCAR, MERRA-2, ECMWF ERA40, and ERA-INTERIM. Solar-Terrestrial Physics. 2019. Vol. 5. Iss. 1. P. 69-76. DOI: 10.12737/stp-51201910. 